\title{
A Pilot Study of Visual Function Parameters and Their Relationship to Road Traffic Accidents among Drivers in Trinidad and Tobago
}

\author{
Kingsley K. Ekemiri ${ }^{1}$, Prashan Seepersad ${ }^{1}$, Ngozika E. Ezinne ${ }^{1}$, Krista Seetaram ${ }^{1} \&$ Niall Farnon $^{1}$ \\ ${ }^{1}$ Optometry Unit, Faculty of Medical Sciences, The University of the West Indies, St Augustine, Trinidad and \\ Tobago \\ Correspondence: Kingsley K. Ekemiri, Optometry Unit, Department of Surgical Sciences, Faculty of Medical \\ Sciences, The University of the West Indies, St Augustine, Trinidad and Tobago. ORCID: 0000-0003-3881-7502.
}

Received: May 16, 2021 Accepted: June 27, 2021 Online Published: July 23, 2021

doi:10.5539/gjhs.v13n9p24 URL: https://doi.org/10.5539/gjhs.v13n9p24

\begin{abstract}
Background: Vision attributes to about $95 \%$ of the sensory requirements for driving. When driving, impaired visual functions will undoubtedly result in a delayed response to obstructions. The regulations governing the issuing and renewal of a driver's license in Trinidad make no provision of a visual requirement assessment. The study was prompted by an upsurge in road traffic accidents in Trinidad and Tobago, a twin-island nation.
\end{abstract}

Aim: This pilot study investigates the relationship between defects in visual functions and traffic accidents among drivers on the island of Trinidad.

Methodology: This descriptive cross-sectional study utilizes a non-probability purposive sampling approach to enroll licensed drivers who had been driving within the island's districts for the past five years, the study conducted at a Multi-Health-Training Facility in Trinidad's Central Area. After completing a semi-structured questionnaire, participants were given a full eye examination.

Results: 128 licensed drivers, both male and female, were enrolled for this study with ages ranging from 20 to 70 years with a mean age of 40.9 years \pm 13.3 years, in which majority $(83.6 \%, \mathrm{n}=107)$ of the drivers did not perform an eye exam before obtaining/renewing their driver's license. About $32 \%(n=41)$ of these drivers were involved in an RTA in the last five years. There was a statistically significant association between colour vision defect $\left(\chi^{2}=\right.$ $15.94, p=0.00)$, contrast sensitivity with a $\log C S$ score of less than $1.52\left(\chi^{2}=25.05, p=0.00\right.$, Cramer's $\left.V=0.442\right)$ and the occurrence of road traffic accident.

Conclusion: According to this study, one-quarter of drivers have been involved in a road traffic accident within the last five years, and three-quarters have never had an eye examination before obtaining or renewing their driver's license. The relevance of designing and developing a screening protocol that can be easily applied to driving safety licensing policies were established in this study. Based on these findings, prospective driver's license applicants must undergo a complete eye examination, to drastically reduce RTAs.

Keywords: visual function, drivers, road traffic accident, Caribbean, Trinidad and Tobago, visual defect

\section{Introduction}

The ability to see is undeniably an essential component of being considered a good driver, as the driving action is heavily reliant on vision for its efficient and proper execution (Pepple, 2014). Clear and comfortable vision is necessary for driving for various reasons, including identifying road traffic signs, identifying traffic lights, and making appropriate decisions to avoid potholes. Driving requires a combination of sensory, emotional, motor, and compensatory abilities. It is primarily a cognitive (thinking) and sensory (vision) activity (Karthaus \& Falkenstein, 2016). Vision accounts for approximately $95 \%$ of the sensory requirements for driving. Impaired visual functions will invariably result in a delayed reaction to obstacles while driving (Owsley, 2010). Thus, a driver's vision would ultimately decide how effectively he can perform, determining the probability of Road Traffic Accidents (RTAs).

RTAs have emerged as a significant public health issue in this century, and they are currently considered a neglected pandemic. Road accidents claim the lives of over 1.3 million people every year. As a result, almost 50 million individuals are disabled, costing most countries $3 \%$ of their gross domestic product (GDP) (Behzadi, 2020). The World Health Organization (WHO) reported that RTAs account for $2.1 \%$ of total deaths and $21 \%$ of total injuries worldwide. Developing countries such as the Islands of Trinidad and Tobago account for $80 \%$ of those 
deaths (Peden, 2005). The rate of fatalities from traffic accidents in the Caribbean region grew from 14.75 to 17.68 deaths per 100,000 population between 2000 and 2010, increasing by 20\% (Gopaul, 2016). Trinidad and Tobago is currently ranked 97th out of 183 countries in terms of RTAs, making it the Caribbean's third highest-ranked country, behind Suriname (79th) and Guyana (94th) (Road Traffic Accidents Death Rate, 2021).

Trinidad and Tobago is a Caribbean twin-island that is a developing nation and the region's economic hub. It saw a boost in the automobile industry in 1995 with the opening of the foreign-used car market, enabling customers to increase their living standards and lead to a higher GDP by purchasing a car (Gopaul, 2016). Road transport is considered the most crucial means for moving goods and people within the Twin Islands. Other alternative means of transport are not an option. The demand for privately and commercially owned cars has increased in the past two decades. During the period 2000-2011, the number of people who died from all causes in Trinidad and Tobago was 119,020 . Of these, RTAs accounted for 2,360 deaths $(\approx 2.0 \%)$ in 2,073 fatal collisions ( $\approx 1.1$ deaths per collision) (Gopaul, 2016).

Driver fitness in Europe is regulated by the European Union (EU) law and locally made legislation in individual jurisdictions. According to the Road Safety Authority (RSA) and the National Office for Traffic Medicine of Ireland, all prospective drivers or drivers already in possession of a driver's license must fit specific Visual Acuity (VA) and Visual Field (VF) criteria. Group 1 license applicants or holders must have a binocular acuity, with a refractive correction, if necessary, of at least 20/40 on a Snellen chart (Rae, 2016). In the United States of America (USA), the testing parameter that varies least from state to state is VA. Georgia requires a Best Corrected Visual Acuity (BCVA) of at least 20/60 in at least one eye. Some states will not issue any driver's license to people with homonymous hemianopia. Evaluating optimal visual functions such as VA, colour vision, depth perception (stereopsis), contrast sensitivity, and peripheral vision are critical in issuing a driver's license or permitted to drive (Steinkuller, 2010). The Trinidad and Tobago Motor Vehicle and Road Traffic Act (1936) legislation give authority to the Ministry of Works and Transportation (MoWT) authority to execute its function in vehicle-related matters such as issuing drivers licenses to eligible drivers were amended in 2017. However, the regulations governing the issue and renewal of a driver's license in Trinidad do not have a specific Snellen or LogMar visual requirement nor a VF angle requirement.

These visual function parameters' importance among drivers cannot be overstated. However, there is a paucity of knowledge on the extent to which they affect drivers in Trinidad. Therefore, this pilot study was conducted to investigate the relationship between visual function parameters and the occurrence of RTAs among drivers. Acquiring this information will contribute to effective policy formulation on the visual aspects of road safety on the island to improve safety on roads.

\section{Method}

\subsection{Study Design}

This descriptive cross-sectional study enrolled drivers in Trinidad using a non-probability purposive sampling approach. Participants had to be Trinidadian citizens, have at least one year of driving experience as a licensed driver, and be between the ages of twenty and seventy. The data was gathered in two ways: ocular examination and semi-structured questionnaire.

\subsection{Sampling Approach}

Public announcements were made across a variety of communication platforms to recruit participants for the study. Participants initially communicated their interest in participating in the survey to the investigators via phone call, email, or instant messaging. A codebook was used to register each participant and confirm their availability for the study; all respondents then provided informed consent. Based on the selection criteria, a total of 128 licensed drivers were chosen for the study.

\subsection{Study Population}

This study comprised various ethnic backgrounds, religious and political beliefs, and the age range of twenty (20) to seventy (70) years. Subjects must have had at least one year of driving experience and a valid driver's license obtained from Trinidad and Tobago's licensing authority. Unfortunately, candidates who are less than twenty years of age, institutionalized or not mentally or physically able to communicate, and those who do not consent to participate in the study were excluded from this study.

\subsection{Data Collection}

The data collection started from January to April 2020 and was obtained from two sources: an ocular examination and a semi-structured questionnaire. The probes in the questionnaires were based on previous studies (Boadi-Kusi 
et al., 2016). The questionnaire was validated using a Cronbach's alpha correlation of 0.75 on ten (10) drivers who did not participate in the study. The main results compared various aspects of visual function, such as the drivers' ability to detect the traffic lights and pass objective colour vision testing criteria. The interviews were conducted by a researcher who had prior fieldwork experience and was retrained for this project. The questionnaire contained sections on socio-demographics, duration of driving, perceived difficulties in driving related to the visual status, and a brief history of their driving experience. However, the driving-related ocular exam provided the researchers with measurements of the driver's current visual status. The tests to examine the ocular status included eight non-invasive procedures conducted by an experienced optometrist in a clinical setting following specific guidelines (Elliott, 2021).

At 3m, VA was measured for each eye with a high contrast LogMAR chart. When VA was less than 0.2 LogMAR, pinhole acuity was used. Disability glare testing - using the $3 \mathrm{~m}$ LogMar chart and a flashlight shone directly below the pupil, the participant is expected to read the smallest letter possible. A hand-held retinoscope (Keeler, 3.6V LED Professional Streak Retinoscope) was used to perform objective refraction on all participants. Certified optometrists optimized the measurements obtained to produce the final spectacle prescription for participants. The TNO fly test was used to measure the drivers' gross and fine depth perception. In contrast, the drivers' colour vision was tested using the Ishihara Colour Deficiency Test (pseudo-isochromatic plate). Following the refraction, the participants were checked for colour vision and stereopsis while wearing their best-corrected spectacle prescription.

Examining the eye's anterior segment with a Slitlamp Biomicroscope (Haag Streit UK) and the posterior segment of the eye using a Volk lens along with the Slitlamp Biomicroscope were also conducted to detect the presence of any pathology. The participants' intraocular pressure (IOP) was measured using an i-care 300 tonometer (Topcon, Canada). In case of further evaluation, participants were referred to the appropriate hospital for attention.

\subsection{Data Analysis}

The data generated from this study were analyzed using the IBM Statistical Package for Social Sciences (SPSS) version 19 for Microsoft Windows 10 Home Edition version 1903. The data was initially entered into Microsoft Excel 2015 Edition. To further categorize the data, a binocular LogMAR score greater than 0.2 was classified as abnormal. A LogMAR score of less than 0.2 binocularly was considered normal, similar to the Drivers' and Vehicular License Act of 1999 (DVLA, 1999). The Intraocular Pressure (IOP) was categorized into two subgroups labelled as "below $22 \mathrm{mmHg}$ ", classified as standard, and above " $22 \mathrm{mmHg}$ ", which was noted as abnormal (Wójcik-Gryciuk et al., 2015). According to the manufacturers of the Mars Letter Contrast Sensitivity Test (The Mars Perceptrix Corporation, 2013), a Log contrast sensitivity (LogCS) of 1.52 or higher was classified as normal, and less than 1.52 was classified as abnormal. "Stereoscopic acuity less than 50" was considered normal, and "scores greater than 50" were deemed abnormal (Lee et al., 2005). These standards were created because there are no set standards and laws in Trinidad and Tobago, which govern a person's visual status to obtaining a driver's license.

The categories of the data and their subcategories were all meticulously transferred and analyzed with SPSS. Cross-tabulation was performed on all data and contingency Chi-square tests on the sub-categorical data. Within the $95 \%$ confidence level, a p-value of 0.05 or less was considered significant, and a Cramer V score was used to measure the strength of the association determined by the Chi-square tests.

\subsection{Ethical Consideration}

The UWI Ethics Committee gave ethical approval to conduct this study with the reference number: CREC-SA.0068/10/2019. After a verbal description of the study's procedures, the licensed drivers gave their consent. The study followed the Helsinki Declaration to the letter.

\section{Results}

\subsection{Socio-Demographics Characteristics of Drivers}

\subsubsection{Age and Gender Distribution}

A total of 128 vehicle licensed drivers were enrolled in the study. Their ages ranged from 20 to 70 years with a mean age $( \pm \mathrm{SD})$ of 40.9 years \pm 13.3 years. Most of the drivers $(27.3 \%, \mathrm{n}=35)$ were aged $20-30$ years, followed by the age group of $31-40$ years $(25.8 \%, \mathrm{n}=33)$, and the least aged ( $61-70$ years) accounted for $(9.8 \%, \mathrm{n}=12)$ of the population (Table 1).

\subsubsection{Level of Education}

Most of the participants had a formal education. Those that completed tertiary education $(48.4 \%, \mathrm{n}=62)$ were the 
majority, followed by "A" levels $(28.9 \%, \mathrm{n}=37)$, and primary education accounted for the least group $(5.5 \%, \mathrm{n}=7)$ considering their level of education (Table 1).

Table 1. Socio-demographic variable $(\mathrm{N}=128)$

\begin{tabular}{lll}
\hline Variables & Frequency & Percentage \\
\hline Gender & 63 & 49.2 \\
Female & 65 & 50.8 \\
Male & 35 & \\
\hline Age & 33 & 27.3 \\
$20-30$ & 25 & 25.8 \\
$31-40$ & 23 & 19.5 \\
$41-50$ & 12 & 18.0 \\
$51-60$ & & 9.4 \\
$61-70$ & 9 & \\
\hline Ethnic Background & 17 & 7.0 \\
White/Caucasian & 49 & 13.3 \\
Hispanic/ Latino & 53 & 38.3 \\
Indo-Caribbean & & 41.4 \\
Afro-Caribbean & 7 & 5.5 \\
\hline Level of Education & 21 & 16.4 \\
Primary School & 37 & 28.9 \\
CSEC Level & 62 & 48.4 \\
A levels/ CAPE & 1 & 0.8 \\
Tertiary Education & & \\
Other & & \\
\hline
\end{tabular}

\subsection{Driving Duration and Obtaining/Renewing License}

The duration of continuous driving among the drivers showed that most drivers drive continuously for $6-10$ hours $(61 \%, \mathrm{n}=79)$. This is followed by $4-5$ hours $(21.1 \%, \mathrm{n}=27)$. The least driving hours among drivers is $>15$ hours $(3.1 \%, n=4)$. One hundred and seven $(83.6 \%)$ drivers reported that they have never had an eye examination before obtaining or renewing their driver's license. Drivers who reported having an eye examination prior to renewing their license account for the fewest participants, approximately $(16.4 \%, \mathrm{n}=21)$ (Table 2).

Table 2. Possession and Mode of Obtaining License by Respondents $(\mathrm{N}=128)$

\begin{tabular}{lll}
\hline Driving License Variables & Frequency & Percentage \\
\hline Possession of driver's license & 128 & 100 \\
Yes & 0 & 0 \\
No & & \\
\hline Eye exam conducted & 107 & 83.6 \\
No & 21 & 16.4 \\
Yes & & \\
\hline
\end{tabular}

\subsection{History of Road Traffic Accident and Drivers Experience}


The majority $(68 \%, \mathrm{n}=87)$ reported "no road traffic accidents" in the previous five years, accounting for two-thirds of the sample population, while one-third $(32 \%, \mathrm{n}=41)$ reported being "involved in road traffic accident" in the previous five years. The driving experience among drivers reflects that the majority $(24.2 \%, n=31)$ of the drivers had 11-15 years of driving experience, followed by $6-10$ years $(23.4 \%, \mathrm{n}=30)$, whereas the least driving experience was $1-5$ years $(13.3 \%, \mathrm{n}=17)$ (Table 3$)$.

Table 3. Experience and Road Traffic Crash History among Respondents ( $\mathrm{N}=128)$

\begin{tabular}{lll}
\hline Driving History Variable & Frequency & Percentage \\
\hline Drivers Experience & 17 & 13.3 \\
1-5 years & 30 & 23.4 \\
6-10 years & 31 & 24.2 \\
$11-15$ years & 24 & 18.8 \\
16-20 years & 26 & 20.3 \\
$>20$ years & & \\
\hline RTA in the last 5 years & 87 & 68.0 \\
No & 41 & 32.0 \\
Yes & & \\
\hline Average Driving Duration & 27 & 21.1 \\
4-5 hours & 79 & 61.7 \\
6-10 hours & 18 & 14.1 \\
$11-15$ hours & 4 & 3.1 \\
$>15$ hours & & \\
\hline
\end{tabular}

\subsection{Contrast Sensitivity and Stereopsis (TNO fly test)}

The findings indicate that drivers in the study had profound $(0.7 \%, \mathrm{n}=1)$, severe $(5.5 \%, \mathrm{n}=7)$, and moderate $(13.3 \%$, $\mathrm{n}=17$ ) contrast sensitivity defects in both eyes. On the other hand, most drivers were considered to have an excellent $\log$ contrast sensitivity score. Within the last five years, the driver has been involved in RTAs with profound $(0.7 \%)$ and severe $(4.5 \%, \mathrm{n}=6)$ contrast sensitivity impairment (Table 4$)$. The cross-tabulation for stereopsis indicates that $36(28 \%)$ drivers had abnormal stereopsis, and $18(13.7 \%)$ drivers had been involved in RTAs within the previous five years (Table 4).

\subsection{Visual Acuity and Glare}

About twenty-six (20.3\%) drivers with visual acuity score of $<0.2$ LogMAR involved in RTAs within the last five years, seventeen $(13.3 \%)$ of the drivers reported reduced VA with a glare in either eye. It can be observed that drivers who had a VA of 0.1 to $0.0 \operatorname{LogMAR}(10.9 \%, \mathrm{n}=14)$ were primarily involved in an RTAs in the last five years in comparison to drivers with a worse VA score (Table 4).

\subsection{Colour Vision (Ishihara Pseudoisochromatic Plate)}

Drivers $(20.3 \%, \mathrm{n}=26)$ with colour vision defects who missed less than 13 Ishihara plates were most frequently involved in RTAs than drivers $(11.7 \%, \mathrm{n}=15)$ who missed more than 13 Ishihara plates. However, most drivers $(62.2 \%, n=80)$ who missed less than 13 Ishihara plates never reported being involved in RTAs within the past five years (Table 4). 
Table 4. Relationship between Visual Function Parameters and Involvement in Road Traffic Accident in the last 5 years $(\mathrm{N}=128)$

\begin{tabular}{|c|c|c|c|}
\hline \multirow{2}{*}{$\begin{array}{l}\text { Vision Parameters } \\
\text { Visual Acuity (LogMAR) }\end{array}$} & \multicolumn{3}{|c|}{ Involvement in Road Traffic Accident in the last 5 years } \\
\hline & No (\%) & Yes $(\%)$ & $\operatorname{Total}(\mathrm{N}=128)$ \\
\hline $0.1-0$ (Excellent) & $40(31.2 \%)$ & $14(10.9 \%)$ & $54(42.2 \%)$ \\
\hline $0.02-0.1$ (Good) & $27(21.1 \%)$ & $11(8.6 \%)$ & $38(29.7 \%)$ \\
\hline $0.12-0.2$ (Normal) & $7(5.5 \%)$ & $1(0.8 \%)$ & $8(6.3 \%)$ \\
\hline $0.22-0.3$ (Moderate) & $12(9.4 \%)$ & $8(6.3 \%)$ & $20(15.6 \%)$ \\
\hline$>0.32$ (Severe) & $1(0.8 \%)$ & $7(5.5 \%)$ & $8(6.3 \%)$ \\
\hline \multicolumn{4}{|c|}{$\mathrm{P}>0.05$ : Statistically not significant } \\
\hline \multicolumn{4}{|l|}{ Stereopsis } \\
\hline $160 "-100 "$ (Severe) & $6(4.6 \%)$ & $5(3.6 \%)$ & $11(8.5)$ \\
\hline $63 ”-50 "$ (Moderate) & $12(9.4 \%)$ & $13(10.1 \%)$ & $25(19.5 \%)$ \\
\hline 40" - 32" (Normal) & $40(31.2 \%)$ & $17(13.3 \%)$ & $57(44.5 \%)$ \\
\hline $25 ”-20 ”($ Excellent $)$ & $29(22.6 \%)$ & $6(4.7 \%)$ & $35(27.3 \%)$ \\
\hline \multicolumn{4}{|c|}{$\mathrm{P}>0.05$ : Statistically not significant } \\
\hline \multicolumn{4}{|c|}{ Contrast Sensitivity (LogCS) } \\
\hline$<0.48$ (Profound) & 0 & $1(0.7 \%)$ & $1(0.7 \%)$ \\
\hline $0.52-1.00$ (Severe) & $1(0.8 \%)$ & $6(4.7 \%)$ & $7(5.5 \%)$ \\
\hline $1.04-1.48$ (Moderate) & $4(3.1 \%)$ & $13(10.2 \%)$ & $17(13.3 \%)$ \\
\hline $1.52-1.76$ (Normal) & $30(23.4 \%)$ & $12(9.4 \%)$ & $42(32.8 \%)$ \\
\hline 1.72-1.92 (Excellent) & $52(85.2 \%)$ & $9(14.7 \%)$ & $61(47 \%)$ \\
\hline \multicolumn{4}{|c|}{$\mathrm{P}<0.05$ : Statistically Significant } \\
\hline \multicolumn{4}{|c|}{ Glare Assessment } \\
\hline No & $60(46.9 \%)$ & $24(18.7 \%)$ & $84(65.6 \%)$ \\
\hline Yes & $27(21.1 \%)$ & $17(13.3 \%)$ & $44(34.4 \%)$ \\
\hline \multicolumn{4}{|c|}{$\mathrm{P}>0.05:$ Statistically not significant } \\
\hline \multicolumn{4}{|c|}{ Colour Vision Assessment } \\
\hline $\begin{array}{l}<13 \text { Plates Missed } \\
\text { (Colour vision defect) }\end{array}$ & $80(62.5 \%)$ & $26(20.3 \%)$ & $106(82.8 \%)$ \\
\hline $\begin{array}{l}>13 \text { Plates Missed } \\
\text { (No defect) }\end{array}$ & $7(5.5 \%)$ & $15(11.7 \%)$ & $22(17.2 \%)$ \\
\hline $\mathrm{P}<0.05$ : Statistically Sign & & & \\
\hline
\end{tabular}

\section{Discussion}

The results of this pilot study revealed that neither gender dominates driving; eligible licensed drivers for this study included males $(50.8 \%, \mathrm{n}=65)$ and females $(49.2 \%, \mathrm{n}=63)$. In contrast, a study conducted in Ghana found that males $(100 \%, \mathrm{n}=520)$ dominated as drivers; however, this study was conducted among commercial drivers in Ghana (Boadi-Kusi et al., 2016). This could be due to the perception that driving is a dangerous task that males are better equipped to handle than females (Martin \& Barnard, 2013). According to the study, the most active driving age groups were between 20 to 30 years old $(27.3 \%)$, with the mean age of 40.9 years \pm 13.3 years, and the age group of 31 to 40 years experienced RTAs more than other groups. A similar study in China supports these findings, showing that drivers aged 18-30 years are more active and more likely to cause accidents (Hu et al., 2020). On the other hand, another study found that Nigeria's most active driving age groups are between 40 and 49 years old 
(Ekpenyong et al., 2020). The active age of 21-29 years is exposed to the risk of a crash. In most cases, due to nighttime driving. This exposure decreases with age. However, the fatality rate is common among the elderly. This can be attributed to their frail nature (Regev et al., 2018).

RTAs have been reported by about one-third of drivers in the last five years, resulting in a prevalence of $32 \%$ for both "major" and "minor" accidents. This result is significantly higher than other studies' prevalence of RTA history, which has been as low as 15.3\% (Biza et al., 2013). 16.2\% (Bekibele et al., 2008) 19.5\% (Oladehinde et al., 2007) 20.8\% (Adekoya et al., 2009) 22.5\% (Boadi-Kusi et al., 2016) 26.5\% (Chidi-Egboka et al., 2017). The variations in the study population may be attributed to the following: sample population size, characteristics of the sample population, research methodology utilized and research funding (Emerole \& Nneli 2013, Boadi-Kusi et al., 2016, Pepple, 2014, Ekpenyong et al., 2020).

Before obtaining a driver's license on the island, all (100\%) participants had to pass a driving test. This is higher than a study conducted in Nigeria's Niger-Delta region (Pepple, 2014) and similar to another study conducted in Ibadan (Nwosu, 1989). The latter study may share similarities attributed to the strict measures implemented by various regulatory agencies in these countries. Most of the drivers had between 11 and 15 years of driving experience. According to the China In-Depth Accident Study (CIDAS), drivers with 6 to 11 years of driving experience cause the most RTAs attributed to driving style and crash propensity (Hu et al., 2020).

In this study, the evidence was insufficient to support the relationship between poor VA, the effect of glare on VA and stereopsis defect. However, the study found that drivers $(20.3 \%, \mathrm{n}=26)$ with colour vision problems and poor vision were frequently involved in RTAs. The research is of value to the visual function of drivers in the Caribbean and Trinidad and Tobago in particular. This is the first pilot study that we are aware of on drivers' visual status concerning RTAs.

This finding identifies more colour vision impaired licensed drivers $(83.8 \%, \mathrm{n}=106)$ than the research done by Tang et al. (2006), where only $9.9 \%$ of the drivers were found to have colour vision defects. A similar study found that drivers with colour defects are more likely to be involved in RTA, particularly protans and deutrans (Boadi-Kusi et al., 2016). On the other hand, studies found that all drivers who missed less than 13 Ishihara plates had never been involved in RTA (Ovenseri-Ogbomo \& Omuemu, 2010, Oladehinde et al., 2007). However, the discrepancy between these studies could be related to the instrument utilized, such as the pseudoisochromatic plate and Hardy Rand and Rittler (HRR) plate, which can detect congenital and acquired colour vision impairments (Ovenseri-Ogbomo \& Omuemu, 2010).

Due to traffic signs and signals, a colour vision defect may jeopardize the driver's ability to drive safely. Protanopia-affected drivers were more likely to miss the red signal from a traffic light, which could have resulted in RTAs (Boadi-Kusi et al., 2016).

A total of 36 (28.1\%) drivers were found to have a stereoscopic acuity greater than 50", with 18 drivers having been involved in an RTA in the previous 5 years and scoring less than 50" in stereoscopic acuity, which follows the findings of Tang et al., who found that $18.5 \%$ of drivers had poor stereo acuity (Tang et al., 2006). Stereopsis had a positive effect on driving performance only in dynamic situations at intermediate distances, according to a study investigating the impact of stereoscopic depth perception on automobile driving performance (Bauer et al., 2001). Another survey of $15.4 \%$ of drivers with abnormal stereopsis found that $5.2 \%$ of these drivers admitted to having difficulty judging distance when driving (Boadi-Kusi et al., 2016).

Correlational analysis showed that on performing a Chi-Square test on the VA, it was further categorized into candidates having a binocular VA better than 0.2LogMar or worse than 0.2LogMar. Chi-Square test revealed a relationship between the VA being less than 0.2LogMar and RTA occurrence in the last five years $(\mathrm{p}<0.05)$. However, a Cramers V score of 0.244 indicates a weak relationship, which is consistent with the findings from Odisha, India, where it was discovered that there was no significant relationship between refractive error and RTA (Kshatri et al.).

However, 42 (32.8\%) of the drivers studied scored below the standard limit of 1.52 Log CS unit. Crosstable data analysis revealed that most $(31.7 \%)$ of the RTA occurred with drivers considered to have moderate contrast sensitivity (Log CS unit 1.04-1.48). The Log CS unit score worse than 1.52 being abnormal revealed an association $(\mathrm{p}<0.05)$ with RTAs. This relationship was amplified with a Cramers V score of 0.442 . This finding is similar to the one obtained in the North-Central State of Nigeria conducted by Chidi-Egboka et al., where it was discovered that there was also an association with Contrast Sensitivity Impairment and RTA (Chidi-Egboka et al., 2017). The Chi-Square, $\chi^{2}$ test revealed no statistical relationship between having a stereoscopic acuity worse than 50 " and RTA occurrence in the last five years $(\mathrm{p}>0.05)$. 
Ultimately, this study revealed that approximately $25 \%$ of drivers had been involved in RTAs in the past five years, and $75 \%$ of these drivers had never had an eye exam before obtaining or renewing their driver's license. It also discovered a relationship between the occurrence of RTAs in the past five years and abnormal colour vision and contrast sensitivity.

\section{Conclusion}

This study established the importance of adopting and developing a screening protocol that can easily be translated into driving safety licensing policies. Based on these findings, a mandatory comprehensive eye examination for prospective driver's license applicants is necessary. This will contribute significantly to the reduction of RTAs. A robust partnership approach between the Ministry of Works and Transportation's Licensing Office in Trinidad and Tobago, the Trinidad and Tobago Optometry Association (TTOA), and other stakeholders is critical to ensuring proper screening before the issuance of a driving license, both initially and during renewals.

\section{Acknowledgements}

The authors gratefully acknowledge the staff and students' collaborative support at the Optometry unit, The University of the West Indies, Couva Multi Training Centre. The authors also acknowledge Dr Subash Sharma and Dr Jan Bohringer for their encouragement and support during this research project.

\section{Competing Interests Statement}

The authors declare that there are no competing or potential conflicts of interest.

\section{References}

Adekoya, B. J., Owoeye, J. F., Adepoju, F. G., \& Ajaiyeoba, A. I. (2009). Visual function survey of commercial intercity vehicle drivers in Ilorin, Nigeria. Canadian journal of ophthalmology. Journal canadien d'ophtalmologie, 44(3), 261-264. https://doi.org/10.3129/109-049

Bauer, A., Dietz, K., Kolling, G., Hart, W., \& Schiefer, U. (2001). The relevance of stereopsis for motorists: a pilot study. Graefe's Archive for Clinical and Experimental Ophthalmology, 239(6), 400-406. https://doi.org/10.1007/s004170100273

Behzadi, A., Shahba, M., Etemadi, S., Mohamadi, B., Karvar, M., Jafari, Y., \& Hedayatipour, M. (2020). Epidemiology and cost-analysis of emergency department patients treated following traffic accidents in Iran: A retrospective cross-sectional study. International journal of critical illness and injury science, 10(4), 182-188. https://doi.org/10.4103/IJCIIS.IJCIIS_93_19

Bekibele, C. O., Fawole, O. I., Bamgboye, A. E., Adekunle, L. V., Ajav, R., \& Baiyeroju, A. M. (2008). Risk factors for road traffic accidents among drivers of public institutions in Ibadan, Nigeria. African Journal of Health Sciences, 14(3). https://doi.org/10.4314/ajhs.v14i3.30860

Biza, M., Mossie, A., Woldemichael, K., \& Gelaw, Y. (2013). Visual impairment and road traffic accidents among drivers in Jimma Town, Southwest Ethiopia. Ethiopian medical journal, 51(2), 123-132.

Boadi-Kusi, S. B., Kyei, S., Asare, F. A., Owusu-Ansah, A., Awuah, A., \& Darko-Takyi, C. (2016). Visual function among commercial vehicle drivers in the central region of Ghana. Journal of Optometry, 9(1), 54-63. https://doi.org/10.1016/j.optom.2015.06.004

Chidi-Egboka, N. C., Bolarinwa, O. A., Awoyemi, A. O., \& Patrick, C. (2017). Eye care practices among commercial drivers in a developing country. Research Journal of Health Sciences, 5(2), 82. https://doi.org/10.4314/rejhs.v5i2.4

Driver and Vehicle Licensing Authority Act, 1999 (ACT 569). Cedidollar. (2019, January 16). https://www.cedidollar.com/driver-and-vehicle-licensing-authority-act-1999-act-569/

Elliott, D. B. (2021). Clinical procedures in primary eye care. Elsevier.

Gopaul, C. D., Singh-Gopaul, A., Sutherland, J. M., Rostant, L., Ebi, K. L., \& Chadee, D. D. (2016). The Epidemiology of Fatal road traffic Collisions in Trinidad and Tobago, West Indies (2000-2011). Global health action, 9, 32518. https://doi.org/10.3402/gha.v9.32518

Hu, L., Bao, X., Wu, H., \& Wu, W. (2020). A Study on Correlation of Traffic Accident Tendency with Driver Characters Using In-Depth Traffic Accident Data. Journal of Advanced Transportation, 2020, 1-7. https://doi.org/10.1155/2020/9084245

Karthaus, M., \& Falkenstein, M. (2016). Functional Changes and Driving Performance in Older Drivers: Assessment and Interventions. Geriatrics (Basel, Switzerland), $1(2), \quad 12$. 
https://doi.org/10.3390/geriatrics1020012

Kshatri, J. S., Pradhan, P. C., Patro, S., \& Tripathy, R. M. (2016). Ocular Status of Inter-State Commercial Drivers: A CrossSectional Study in Odisha, India. International Journal of Ophthalmic Research, 2(4), 188-191. https://doi.org/10.17554/j.issn.2409-5680.2016.02.56

Lee, S. Y., \& Koo, N. K. (2005). Change of stereoacuity with aging in normal eyes. Korean journal of ophthalmology: KJO, 19(2), 136-139. https://doi.org/10.3341/kjo.2005.19.2.136

Nwosu SNN: Vision survey of government motor vehicle drivers in Oyo State. May: Fellowship dissertation National Postgraduate Medical College of Nigeria; 1989.

Oladehinde, M. K., Adeoye, A. O., Adegbehingbe, B. O., \& Onakoya, A. O. (2007). Visual functions of commercial drivers in relation to road accidents in Nigeria. Indian journal of occupational and environmental medicine, 11(2), 71-75. https://doi.org/10.4103/0019-5278.34532

Ovenseri-Ogbomo, G., \& Dr V Omuemu. (2010). Prevalence of refractive error among school children in the Cape Coast Municipality, Ghana. Clinical Optometry, 59. https://doi.org/10.2147/opto.s10583

Owsley, C., \& McGwin, G., Jr (2010). Vision and driving. Vision research, 50(23), 2348-2361. https://doi.org/10.1016/j.visres.2010.05.021

Peden, M. (2005). Global collaboration on road traffic injury prevention. International journal of injury control and safety promotion, 12(2), 85-91. https://doi.org/10.1080/15660970500086130

Pepple, G., \& Adio, A. (2014). Visual function of drivers and its relationship to road traffic accidents in Urban Africa. SpringerPlus, 3, 47. https://doi.org/10.1186/2193-1801-3-47

Rae, S., Latham, K., \& Katsou, M. F. (2015). Meeting the UK driving vision standards with reduced contrast sensitivity. Eye, 30(1), 89-94. https://doi.org/10.1038/eye.2015.188

Regev, S., Rolison, J. J., \& Moutari, S. (2018). Crash risk by driver age, gender, and time of day using a new exposure methodology. Journal of Safety Research, 66, 131-140. https://doi.org/10.1016/j.jsr.2018.07.002

ROAD TRAFFIC ACCIDENTS DEATH RATE BY COUNTRY. (2021). Retrieved 26 June 2021, from https://www.worldlifeexpectancy.com/cause-of-death/road-traffic-accidents/by-country/

Steinkuller, P. G. (2010). Legal Vision Requirements for Drivers in the United States. AMA Journal of Ethics, 12(12), 938-940. https://doi.org/10.1001/virtualmentor.2010.12.12.hlaw1-1012

Tang, Y., Siu, A., \& Chan, H. (2006). Visual Status of Hong Kong Commercial Vehicle Drivers. Retrieved from https://iovs.arvojournals.org/article.aspx?articleid=2393505

The Mars Letter Contrast Sensitivity Test. (2013, June 14). Retrieved from https://marsperceptrix.com/sites/default/files/downloads/MarsLetterCSTestUserManualEnglish.pdf

Wójcik-Gryciuk, A., Skup, M., \& Waleszczyk, W. J. (2015). Glaucoma-state of the art and perspectives on treatment. Restorative Neurology and Neuroscience, 34(1), 107-123. https://doi.org/10.3233/rnn-150599

\section{Copyrights}

Copyright for this article is retained by the author(s), with first publication rights granted to the journal.

This is an open-access article distributed under the terms and conditions of the Creative Commons Attribution license (http://creativecommons.org/licenses/by/4.0/). 